\title{
Disembedded or deeply embedded? \\ A multi-level network analysis of online labour platforms
}

\section{Paola Tubaro}

\section{Affiliations}

CNRS, Université Paris-Saclay, Inria, LRI

\begin{abstract}
This paper extends the economic-sociological concept of embeddedness to encompass not only social networks of, for example, friendship or kinship ties, but also economic networks of ownership and control relationships. Applying these ideas to the case of digital platform labour pinpoints two possible scenarios. When platforms take the role of market intermediaries, economic ties are thin and workers are left to their own devices, in a form of 'disembeddedness'. When platforms partake in intricate inter-firm outsourcing structures, economic ties envelop workers in a 'deep embeddedness' which involves both stronger constraints and higher rewards. With this added dimension, the notion of embeddedness becomes a compelling tool to describe the social structures that frame economic action, including the power imbalances that characterize digital labour in the global economy.
\end{abstract}

\section{Key words}

Digital labour, embeddedness, multi-level network analysis, outsourcing, platform economy.

\section{Corresponding author details}

Paola Tubaro

Bâtiment 660, Université Paris Saclay, 91405 Orsay Cedex, France

Email: paola.tubaro@inria.fr

Phone: +33 169155774 


\section{Introduction: embeddedness in markets, firms and platforms}

Embeddedness, or the idea that economic action is grounded in social structures, has been a founding block of economic sociology for the past few decades. In a path-breaking article, Mark Granovetter (1985) contended that people do not act as atoms in an impersonal market, nor do they passively internalize outside norms: rather, their behaviours result from the history of their relationships and from their positions with respect to other relationships. If Granovetter evoked networks of social relationships metaphorically, subsequent analytical advances (Wasserman and Faust, 1994) firmly established social network analysis at the heart of embeddedness scholarship. Since then, a rich empirical literature has shown that, for example, long-term personal relationships help companies to face the highs and lows of the market (Uzzi, 1996, 1997), and that friendship among managers dampens the worst effects of price competition (Ingram and Roberts, 2000).

This - still growing - current of research interprets network ties in two main ways. When internal to the boundaries of the firm, ties serve to explain how this firm works - who gains knowledge or power internally, or how consensus forms around a decision. When they cross firm boundaries, ties are channels for market relationships - whether competitive or oligopolistic, global or local, trusted/repeated or 'arm's length' (Uzzi, 1997). Put differently, economic sociology implicitly inherits a vision à la Coase (1937) that identifies the firm and the market as two alternative, albeit possibly coexisting, devices for economic coordination.

Rooted in transaction cost economics (Williamson, 1981) the firm-market duality is admittedly not an indigenous concept to sociology. Rather than framing problems as referring to firms vis-à-vis markets, economic sociologists tend to characterize networks as intra- or inter-organizational. Nevertheless, sociology and transaction cost theory converge in recognizing that economic activity requires some degree of organization to avoid chaos: there must be a system for matching actors, spreading information, arranging resources, dividing up the work. Even the market is not the impersonal, automated and cost-free mechanism that neoclassical economics imagined, but needs rules, intermediaries and support services (Favereau and Lazega, 2002). Against this common ground, there is still value in explicitly separating markets from firms, because they elicit different costs, with distinct effects on action. Markets involve search costs, bargaining costs, and policing/enforcement costs, while firms entail costs for planning, assigning activities to members and delegating authority. Carruthers and Uzzi (2000) claim that within sociology, the study of the firm has started earlier, and progressed faster, than the study of the market.

This distinction gains new relevance today, as many salute the rise of digital platforms (Srnicek, 2016) as an intermediate form of coordination, between the firm and the market. However debatable, this characterization challenges the conceptualizations and practices of economic sociologists: can the notion of embeddedness and its common operationalization through social network analysis be transposed to digital platforms? If not, what aspects of our thinking should change?

Beyond their interest for scholars of the platform economy, these interrogations re-open the broader question of whether the notion of embeddedness, as shaped by Granovetter's influential article, succeeds in integrating economy and society. Critics do not much challenge the capacity of today's embeddedness research to shed light on the firm, but are dissatisfied with its representation of the market. Krippner (2002) claims that economic sociology still follows neoclassical economics in presupposing the existence of a core asocial market which uncomfortably sits surrounded by society. In no other area are these issues more apparent than in labour inter-mediation - if we believe with Coase $(1937$, p. 392) that labour services are most relevant to determine the arbitrage between firm and market, other production inputs being easier to accommodate into one or the other form. What previously dormant implications of the concept of embeddedness can come to the surface, if we stretch it to embrace (labour) platforms?

To address these questions, I extend and develop Granovetter's concept of embeddedness by drawing on 'multi-level network analysis', in a manner appropriate to a sociological grasp of the 
platform economy. The purpose of this paper is to contribute theoretically to our understanding of embeddedness and conceptually to our understanding of platforms in the digital world. To ensure comparability with recent literature (Wood et al., 2019), I narrow down my analysis to the case of online labour, where digital platforms allocate tasks and jobs to providers who execute them remotely from their laptops or smartphones. My argument is primarily conceptual, though informed by extensive empirical observation of the changing landscape of today's digital economy. The data sources that substantiate my reasoning support a secondary contribution of the article, which elucidates the under-researched vendor-type relationships that some platforms adopt.

I show that the common interpretation of Granovetter's embeddedness in terms of social networks of individuals - peers, friends, relatives - is limiting. Drawing on the multi-level approach proposed by Brailly et al. (2016), I extend the concept of embeddedness to also encompass economic networks, which include combinations of firm-to-firm and individual-to-firm networks. This juxtaposition brings to light the linkages between platforms' business models, their structure of commercial ties, and workers' individual contributions. Two configurations can be observed: when platforms take the role of market intermediaries that connect workers and clients, economic ties are weak regardless of social ties, and workers are left to their own devices, in a form of disembeddedness. When platforms take on management roles akin to firms, economic ties take highly complex forms with multiple layers of contractors, brokers and suppliers that frame the activity of the individual. These layers constitute a structure that is evocatively reminiscent of complex neural networks in so-called 'deep learning', and I thus propose the notion of 'deep embeddedness' to describe them.

The discovery of deep embeddedness has three main implications. Substantively, it contributes to the empirical literature on the platform economy by shedding light on the variety of business models of online labour platforms and their effects on workers. Epistemologically, it demonstrates the value of enhanced dialogue between sociology and social network analysis. Theoretically, it indicates that the relationships that matter are not only personal ones such as friendship or kinship, but also economic ones - relations that describe who owns which hardware and software tools, who recruits workers, who monitors quality. Augmented to include more diverse sets of relationships, Granovetter's original intuition is capable of synthesizing both the social relations that form the context of economic action, and the economic relations that define actors' position in the production system. It is therefore more powerful than its critics contend, and can respond to concerns that economic sociology focuses too much on personal ties while paying insufficient attention to productive structures. An integrated understanding of Granovetter's proposition, enriched with insight from recent network research, has value for analysing contemporary economic changes.

\section{Conceptions of embeddedness: from Polanyi to Granovetter and beyond}

Long before Granovetter (1985), the concept of embeddedness can be found in the highly influential work of Karl Polanyi (1944) where it took a broader, more comprehensive meaning. According to Beckert (2009), it encompassed the limits that institutions and the moral fabric of society impose on economic transactions, while also alluding to the normative task of stabilizing the organization of society through the institutional regulation of the economy. However, Peck (2013) identifies a sharp contradiction in Polanyi, who argued in some places that all economic activity is always 'embedded and enmeshed in institutions economic and noneconomic' (Polanyi, 1957), but proposed a more radical view elsewhere, stressing the disembedding of the 'fictitious commodities' of labour, land and money and the importance of macro-level legal, normative and cultural constraints that limit commodification. Peck (2013) refers to the former as 'soft Polanyi' and to the latter as 'hard Polanyi'.

In this perspective, the work of Granovetter (1985) is a development of the soft Polanyi oblivious of the hard version. A specific criticism pertains to the social networks approach that has quickly come to dominate much of economic sociology after Granovetter's contribution (Krippner, 2002; Beckert, 2003). It has been noted that emphasis on social networks of inter-individual ties (hereafter I-I, left 
panel of figure 1) of friendship, collaboration and trust is the context of economic action but is not constitutive of it (Bandelj, 2020). More seriously, it abstracts away the productive relations of capitalism, those defined around ownership and control of means of production (Calnitsky, 2014).

Research on global commodity chains, global value chains and more recently, global production networks (GPN) also inherits Granovetter's view that economic organization is socially embedded (Henderson et al., 2002). Here, networks are construed as sets of inter-firm relationships in global industries rather than personal ties (Bair, 2008), and include for example supply contracts between firms $(F-F$, represented as thick black lines in the central panel of figure 1$)$. Using the terminology proposed by Hess (2004), 'network' embeddedness is the focus of much economic sociology, while GPN research emphasizes 'territorial' and 'societal' embeddedness, that is, the simultaneously local and trans-local anchoring of economic activities in political, institutional and cultural backgrounds (later also acknowledged by Granovetter in Krippner et al., 2004). The local and non-local dimensions affect each other, both reinforcing embeddedness (Glückler, 2001). But despite its emphasis on economic instead of social ties, the GPN literature long disregarded labour (Barrientos, 2013), and efforts to integrate it are still rare and inhomogeneous (see for an example Pun et al., 2020).

Arguably, these literatures struggle to account for the employment (and related) contracts that according to the power distribution and regulatory framework of society, affiliate individuals to firms $(I-F$, grey lines in the central panel of figure 1$)$. To the question of 'who is embedded' (Hess, 2004), they do not respond 'workers': even individuals I are most often owners or managers, anyway not apprehended as labourers in relation to capital. In contrast, Polanyian approaches allow thinking in terms of workers' (dis)embeddedness (Wood et al., 2019).

Recent advances in social network research, notably the re-framing of the concept of embeddedness as a multi-level problem, have potential to fill these gaps. Against the common practice of separating analysis of inter-individual and inter-firm networks, Brailly et al. (2016) study them jointly, each constituting a level - that is, a self-contained set of actors with collective agency - in a multi-level analysis (Snijders and Bosker, 2012). Within-level ties I-I and F-F are 'horizontal' (between peers), while cross-level $I-F$ ties are 'vertical' (between actors with distinct degrees of decision-making power) and can be seen as bipartite affiliation networks (Breiger, 1974). Each level has its specific processes, yet they are partly nested and inter-dependent.

This approach can be leveraged to reconcile and integrate social $(I-I)$ and economic $(I-F$ and $F-F)$ networks, horizontal $(I-I$ and $F-F)$ and vertical $(I-F)$ ones. They co-evolve as $I-I$ relationships emerge out of $F-F$ relationships, and in turn transform them (through, say, collaborations or working groups). If $I-F$ ties define individuals' access to firm resources, $F-F$ ties modify this opportunity structure by opening and/or closing channels toward resources. By linking these dimensions together (right panel of figure 1), network analysis can link social ties such as friendship and trust to the economic positioning of individuals in production processes. A multi-level approach can thus address the criticisms of network-based operationalizations of Granovetter's embeddedness. Specifically in the case under study, a dual focus on both individuals and firms can reveal the mechanisms through which salaried employment contracts 'embed' individual workers into (for example) local labour regulations, and measure the effect of alternative arrangements.

\section{FIGURE 1}

Do these ideas suffice to take on board the insights that Polanyi's readers miss? Because of their specificities, digital labour platforms are the ideal terrain to probe their relevance and generality. I now briefly review definitions of platforms with specific focus on online labour, before linking them explicitly to debates on embeddedness. 


\section{A case study: Platforms for online labour}

In essence, platforms are intermediaries that leverage digital technologies to coordinate distinct groups of economic actors. The engineering literature defines them as extensible hardware or software functionalities to which third-party modules can be added (de Reuver et al., 2018), while 'multisided' market economics (Rysman, 2009) insists on so-called 'network externalities', whereby a large number of users on one side (for example, car drivers) triggers participation on the other side (passengers). The platform captures the value of these externalities, which can occur within and/or across sides: hence, its user-base is one of its main assets. To increase its size, the platform may subsidize the more price-sensitive side (for example, users of a search engine who access the service for free) at the expense of the other (advertisers, who bid for 'eyeballs' in dedicated auctions).

\section{Digital platforms and embeddedness}

Digital platforms challenge the established distinction between firm and market as economic coordination devices (Sundararajan, 2016, pp. 78-79). Are they just another instance of firms or of markets, a hybrid, or a third way? Particularly interesting in this respect are labour platforms, which bring together clients and workers to buy and sell 'gigs'. Because these workers are recruited on demand and their commitment ends as soon as their output is delivered, they are legally not employees. But because they are rarely free to shape and manage their work, they are not fully independent providers either. Labour platforms blur the economic firm-market duality as much as the legal notion of an employer-employee relationship (De Stefano, 2016). Before studying how labour platforms interrogate our understanding of embeddedness, I describe them in more detail.

\section{Online labour platforms}

Existing typologies of labour platforms (Howcroft and Bergvall-Kåreborn, 2019; Schmidt, 2017) share two common criteria despite differences in terminology. One is the extent to which work is performed offline while inter-mediation occurs online, in comparison to all-online labour platforms. The former category encompasses, among others, platforms for food delivery, urban transport and cleaning, while the latter includes platforms for non-manual work such as design, computerprogramming, accounting, transcriptions, translations, and data entry. The other main criterion distinguishes platforms that allocate jobs in full, as whole projects to individual professional freelancers (design of a company logo or translation of an appliance manual) or small parts of it to myriad non-specialists ('micro-tasks' such as labeling objects in images, recording utterances, transcribing short audio clips). The artificial intelligence (Al) industry uses micro-tasking services to prepare data for its algorithms and to check and/or correct outputs (Tubaro et al., 2020).

With loose geographical boundaries, workers on all-online platforms are exposed to wide competition that drives remunerations down and sometimes induces unconventional working hours or overtime - for example, to meet demand from clients in different time zones (Graham and Anwar, 2019). Thus, the conditions for embeddedness may be more difficult to meet. Shevchuk and Strebkov (2018) find that Russian-language freelancers suffer severely from client-side opportunism and bear financial losses on these platforms. Wood et al. (2019) do find instances of embeddedness in the sense of Peck (2013)'s 'soft Polanyi', which is also similar to the view of Granovetter (1985): many of the workers they observe rely on their peer networks of, say, friends and family to get tasks done. However, these workers are disembedded in the 'hard Polanyi' sense that sees embeddedness as absence of commodification: without labour regulations and rights, they are exposed to fluctuations in the global online market, and have limited access to healthcare and social protection.

It is tempting to try and generalize these ideas to other areas - notably micro-work, the other main sub-category within all-online platform labour, where labour rights and welfare are equally absent. In 
terms of peer networking, however, results from the literature are mixed. A team at Microsoft Research mapped the communication ties of Amazon Mechanical Turk micro-workers and found that they constitute a structured network (Yin et al., 2016). In a related ethnographic study across four different platforms (Gray et al., 2016), they found collaboration, sometimes spontaneously recreated by workers regardless of platforms' unsupportive policies. But before interpreting these results as evidence of micro-workers' network embeddedness, two caveats are in order. First, in their network maps, only $13.4 \%$ of workers are connected, so that there is a long tail of disembeddedness as per Granovetter's original definition. Second, the network is enabled by forums, created for Mechanical Turk but not always available elsewhere.

These studies place emphasis on the social networks of peers $(I-I)$, but they remain silent on the economic ties $I-F$ that link individuals to firms (or platforms), and on any economic linkages between firms/platforms $(F-F)$. To simultaneously address the two, I now explore platform business models and probe them against the above-outlined multi-level view of embeddedness.

\section{An inventory of platforms}

While the reasoning undertaken here is mainly conceptual, it is also informed by my fieldwork experience and draws, if only to an extent, on a comprehensive study of micro-work in France, undertaken in 2017-19. The country features a mix of international platforms (operating mostly in English) and local ones (mostly in French, to cater to the needs of clients who require language proficiency or local knowledge). Interested readers will find more details in Casilli et al. (2019).

The dataset that I use here consists essentially in a detailed inventory of online labour platforms and mobile applications, with information on their company structures, business models, history, location, financial situation, marketing strategies and human resources. A total of 23 platforms in use in the country in 2018, and 5 international ones, have been identified, combining information from varied sources. Once compiled and double-checked for completeness, this list was enriched with details taken from platforms' websites, press releases, media features, and personal communications with founders or managers. The majority of these platforms offer online-only micro-working services, though some do so secondarily relative to another main activity, such as full-fledged freelancing services (like design and computer programming). The broad scope of the inventory allows comparisons across cases and types (notably micro-work and freelancing), and helps to distinguish widespread practices from any idiosyncrasies.

As a complement to this data, I use a set of 92 in-depth interviews with online workers, clients, platform staff and other stakeholders, mostly though not exclusively based in France. For the purposes of this paper, interviews are solely meant to provide concrete examples of configurations that may seem otherwise abstract or unfamiliar, and to support my interpretation of results.

\section{Platform business models and embeddedness}

Observation of the selected platforms indicates that they adopt two main types of business models. I now illustrate them, before discussing how these elements inform the analysis of embeddedness framed above.

\section{Platforms as markets: intermediaries}

Some of the observed platforms function just as classical textbook cases of multi-sided market intermediaries. The prototypical example of this mode of functioning is Amazon Mechanical Turk. The platform organizes interactions between two user groups, workers on one side and clients ('requesters') on the other, and provides the technical infrastructure upon which their activities 
occur. This model mimics a lean, decentralized marketplace where the intermediary is simply a facilitator, and decisions are left to clients (how much to pay for a task, how many workers should complete it, how long it should be available on the site) and to workers (what tasks to do).

For the system to run as smoothly as possible, the platform offers multiple built-in functionalities so that it can host the whole process internally, end-to-end (figure 2, top panel). Once logged in, workers browse and choose from available tasks. They accept the conditions imposed for these tasks (if different from the general Terms of Use of the platform), execute and submit them, and claim payment. On the client side, the platform displays a range of tools and templates to design tasks, post them on the site, review and accept (or reject) workers' submissions, and make payments at the end. On Mechanical Turk, all these functions are accessible through an API (Application Programming Interface) that obviates the need for any other form of personal contact between clients and workers. From the viewpoint of the requesting client, the transaction is hardly distinguishable from any remote procedure call, completely de-personalizing the labour relationship.

\section{FIGURE 2}

After the successful launch of Amazon's market-oriented model in the mid-2000s, other microtasking platforms such as Microworkers have adopted variants of it. A recent tendency is to split the clients' and workers' sides: for example, the former French platform Foule Factory now consists of two sister companies, Wirk.io that sells services to clients and Yappers.club that manages workers. Qualified freelancing platforms like those observed by Wood et al. (2019) also function as market-like structures. The main difference is anonymity. On micro-working platforms, workers' names and personal characteristics are invisible (and largely irrelevant) to clients, and the reverse is often also true: on its website, Wirk.io promises never to tell workers who they do tasks for. Instead, freelancing platforms like Upwork and (in France) Malt allow, or even encourage personal contacts between clients and workers. Malt lets clients select professionals based on their reputation scores and portfolio of past projects, instead of letting undifferentiated workers get tasks on a first-come, first-served basis as on Mechanical Turk. Another distinction is that freelance remunerations are usually not fixed and equal for all participating workers, but negotiated on a case-by-case basis.

Workers navigate marketplace-like platforms alone, and spend considerable time searching for requests, applying and waiting for work (Wood et al., 2019). On Amazon Mechanical Turk, long search time and unpaid tasks result in a large gap between the \$11 per hour that requesters pay on average, and the median hourly wage of $\$ 2$ that workers earn (Hara et al., 2018). Coping strategies demand effort: T., a fifty-year old micro-worker from Southern France, keeps several windows open on her screen (one for each platform she has registered with), with a tool to refresh them automatically, in order to watch for new tasks and switch to better-paid assignments on the fly.

In turn, clients struggle to monitor external contributors, as platforms' reputation systems are often insufficient to guarantee engagement or performance. Quality assurance is expensive and may consist in having several workers do the same task and choosing the majority solution, or posting follow-up tasks that ask workers to check the outputs of others (Vaughan, 2018). Clients' demand for quality increases, as data security becomes a major concern for large companies that use proprietary datasets and that need to protect their activities from the gaze of competitors (Tubaro and Casilli, 2019). Thus, clients become wary of generalist platforms where anyone can see the posted tasks and, worse, unidentified contributors can access the underlying data. Likewise, personal data cannot be given to 'Turkers' according to H., co-founder of a Parisian start-up producing voice assistants, and user of micro-tasking platforms. Another challenge to Amazon's model stems from the growing 
demand, especially by hi-tech clients in the field of Al development, for specialist software infrastructures with state-of-the-art customized features (Schmidt, 2019a).

\section{Platforms as firms: multiple layers}

In an alternative model, the workforce is managed through vendor relationships on behalf of (mostly large) corporate customers. In this case, the organization of the workflow is managed almost like in a firm or group of firms, which centralize most transactions and use contracts rather than the price system to ensure coordination. Champions of this model are large and well-known actors of the global digital data business, Appen, Lionbridge and Pactera. The German Clickworker adopts this model for part of its business - the other part functioning as a marketplace. Like other platforms, these ones avoid employing workers for a salary; but unlike Amazon's model, they arrange tightlyknit outsourcing networks of providers and intermediaries coordinated through a set of contracts and common infrastructures. Quasi-centralized direction distinguishes them from platform-as-market models, while multiplicity of corporate actors demarcates them from classical firms.

These platforms are less transparent than marketplace-like ones, and because they mostly offer bespoke contracts to clients, the general conditions stated on their websites are little detailed. Interviews with workers are difficult to obtain as many of them are bound to non-disclosure agreements. Therefore, it took a painstaking and systematic observation protocol - including all sorts of sources, from websites and reports to webinars and financial communications to investors - and a thorough outreach effort toward willing informants, to reconstitute how the whole work process is sliced into several 'layers' with different interlocutors in each of them (figure 2, bottom panel).

An interview with a female micro-worker illustrates concretely what these layers are. A 30-year-old resident of South-Eastern France, J. was contracted by a Chinese platform as a transcriber on behalf of an American client, the producer of a voice assistant. J. had to listen to recordings of the interactions of French users with this assistant, check them against the automated transcriptions done by the assistant, and correct any errors. She was aware of micro-workers in neighbouring countries that did the same tasks in other languages, and they all reported to a subcontractor in Italy who managed day-to-day practicalities. She received US tax forms for the income she earned.

More generally, the first layer often consists of jobbing websites where potential new workers see advertisements of earning opportunities. They apply and go through a selection process, which may include an interview or exam, and is managed by the vendor that posted the ads - for example Appen - or one of its subsidiaries. Selected workers then sign a contract, sometimes with another partner company. In contrast to market-like platforms where labour is systematically paid by piecerate, here contracts often specify a regular amount of daily or weekly time that the worker commits to, and remuneration is hourly. J. had to do ten hours a week, but sometimes she was given as many as 35 hours, sometimes as few as two and half, depending on clients' demand. A., a 40-year-old mother of two who lives in a rural area, did 20-30 hours a week for over three years, at a pay of $€ 15$ per hour - higher than the French minimum wage, and much higher than the $\$ 2$ of Mechanical Turk!

Contracted-out workers are then directed to the platform that provides the technical infrastructure to execute tasks. This is often a closed, proprietary platform belonging to the final client, a monopsonist: for example UHRS (Universal Human Relevance System) for Microsoft or RaterHub for Google. Management is often entrusted to another sub-contractor, notably if there is bespoke technical infrastructure that requires development or maintenance. Custom-made, Al-enhanced production tools are often provided, to partly automatize the process and save labour costs, and/or to increase the precision of workers' outputs - for example to achieve pixel-level rather than approximate recognition of objects in images (Schmidt, 2019a). Partly because of their high technical level, the functioning of these operational platforms is highly confidential, with no access allowed from the outside and often, no public web page. I could see their interfaces only indirectly during 
fieldwork, as some interviewees accepted to show their screens or pictures they took of them though very discreetly because of non-disclosure agreements. They had got access to UHRS via Clickworker or Pactera, to RaterHub via Appen or Lionbridge.

Because the system is tightly managed and deals with large orders, workers enjoy more predictable working hours (and remunerations) than on market-like platforms. Although A. considers this activity temporary and plans to change job when her children grow up, she is relatively satisfied. She also signed up with a marketplace platform but does not find it interesting, and uses it rarely.

Some of these platforms that Schmidt (2019a) qualifies as 'second generation' in comparison to earlier market-like models à la Mechanical Turk, know their workers and set up quality assurance schemes like firms do: careful selection of who does what tasks, attribution of monitoring responsibilities to motivated workers, creation of qualified teams to do more complex tasks together. These structures are more expensive for clients but offer greater confidentiality and security.

There is even evidence that providers in India, Indonesia, the Philippines, and parts of Africa set up offices where they manage teams of local micro-workers operating in the same premises (Graham et al., 2017; Graham and Anwar, 2019; Roberts, 2019; Schmidt, 2019a). More similar to traditional outsourcing chains, such arrangements appeal to large-sized companies owing to the relatively low cost of labour and the high technical expertise in these countries (Murali, 2019). Such solutions are less frequently observed in Western countries, and beyond the means of smaller clients. C., a Parisian engineer working for a start-up that intensely uses micro-tasking services, reckons that only US tech giants have onsite facilities to recruit micro-workers under controlled conditions, for example when secure access to data or strict quality protocols are required.

\section{Platform-market, platform-firm and embeddedness}

How do the preceding remarks relate to the concept of multi-level embeddedness? Leaving momentarily aside the inter-individual network of social ties $I-I$, the above discussion of business models can help reconstitute the two economic networks F-F (inter-firm) and I-F (individual-firm).

In the platform-as-market model, there is no F-F network of ties between firms. Clients act autonomously of one another, with the platform as their only interlocutor. If there is a network, it is star-shaped, with the platform at its centre. Similarly, affiliation ties $I-F$ are evanescent. They are certainly not employment ties, and almost disappear in micro-work where clients and workers are disconnected. C., the engineer, complained that 'when there is a technical problem, we have no way to realize unless the platform staff tells us, but it is often too late'. Under these conditions, decisions at the client $(F)$ level affect outcomes at the worker $(I)$ level, but there is hardly any inter-level feedback. In sum, the platform-as-market model comes with disembeddedness in a multi-level sense - whether or not workers are embedded in the narrow sense of having a network of peers $I-I$.

Instead, the platform-as-firm model generates dense economic networks, as those described in much GPN scholarship. The inter-firm F-F network consists of the contractual agreements between a lead firm (for example, Microsoft and its proprietary service UHRS), its vendors (such as Pactera), their subcontractors (in charge of, say, maintaining the technical infrastructure) and any additional service providers (like jobbing websites). As before, the affiliation network $I-F$ includes no proper employment relationships, but it ties workers to the company or platform which contracted them out, the final client who (hopefully) files tax documents for them, the subcontractors who provide technical tools. Anonymity vanishes, particularly with large or repeated orders. Like the 'labour chains' described by Barrientos (2013), these platforms dissociate the producer who buys labour force and the recruiter(s) in charge of worker hiring, management and payment - though unlike them, platforms are neither formally registered staffing services, nor informal/illegal intermediaries.

Here, manifold intermediaries replace employment relationships, and even non-salaried workers have access to services, production tools or supervision. Workers renounce some of the flexibility 
and autonomy that market-like platforms like Mechanical Turk offer, to accept discipline (the amount of work they commit to do regularly) and sometimes supervision by others. In exchange, they obtain better pay and a more regular flow of tasks. Gray et al. (2016) also suggest that contractors' internal organization may enable mentoring and skill-building in ways that would be impossible on Mechanical Turk. There is a form of embeddedness here, deriving solely from the position of workers in network structures that superpose distinct sources of agency at individual and firm levels. If these are mainly contractual ties, they inevitably include a human element - as any form of 'relational work' that deploys sociality as part of intentional efforts toward productive or monetary goals (Bandelj, 2020). For example, J. was very happy of her Italian manager who was 'really into the job', always ready to help even at weekends. His availability helped her define her place in the structure, negotiate her duties and make sense of her work. In this sense, F- $F$ ties extend the opportunity structure of individuals (including workers) and to an extent, offset the effects of shabby $I-F$ ties that fail to offer the protections of salaried employment.

This form may be dubbed 'deep' embeddedness, following an intuition of Casilli et al. (2019) who talk about 'deep labour' platforms to highlight the apparent similarity between their multi-layer structure and the complex neural networks that constitute the building blocks of the mathematical field of deep learning, whose 'layers' are containers that receive input, transform it and pass results to the next layer. The reference to deep learning, a prominent technique in today's Al research, points to the role of this industry both as a major client of micro-work and as an input provider that codetermines the structure of $F-F$ and $I-F$ networks. The platform Figure Eight, now part of Appen (2019) uses the metaphor of the 'human-in-the-loop' (with the ' 8 ' symbolizing the loop) to denote the dual involvement of micro-workers and Al tools. Together with workforce recruiters and payment system providers, Al start-ups contribute to shaping the economic networks that surround client(s) and workers, where the joint contribution of humans and semi-automated solutions ensures quality control and monitoring.

As in deep learning, some layers are 'hidden', meaning that the whole structure is hard to see, especially in corporate nets that stretch globally. Varied arrangements to source labour may coexist: if platform systems with non-employed, formally independent workers are the most common, some layers may include salaried temporary workers managed in-house or through dedicated suppliers (for example, Appen offers all these options depending on clients' needs). The latter solutions are little visible because they mostly serve to deal with confidential data - so that workers have to sign stringent non-disclosure agreements - or to discreetly outsource part of production to lower-cost locations overseas. More generally, the contribution of all forms of platform labour to datafied production processes is often left in the shadow (Gray and Suri, 2019). Corporate communication highlights the role of technology, not human contribution, especially in the Al industry (Tubaro et al., 2020; Casilli, 2019; Schmidt, 2019a). In this sense, deep embeddedness means that these multi-layer structures integrate labourers and control their activities, while obfuscating their role.

Under deep embeddedness, I-I social networks among individual workers may or may not exist. Some multi-layer platforms invest in the creation of networking tools for their workers via online forums and chats, in the hope of increasing their engagement (Schmidt, 2019a, p. 37). But the siloed architecture of other platforms restricts interactions among workers: for example on UHRS, different vendors manage the workforce and the few existing discussion boards are internal to each of them and thus asynchronous (Gray et al., 2016).

Despite the better remunerations and working conditions that deeply embedded platforms offer, precariousness and opaqueness still plague micro-work. Continuously evolving Al technologies generate ever new layers of automation, and economic cycles prompt ever new layers of offshoringoutsourcing (Schmidt, 2019b), resulting in large swings in demand for platform labour. Micro-workers may be dismissed at any time, with immediate effect and no explanation. This is what occurred to $A$. after three years almost full time, and to F., a 25-year-old man from Northern France who used to micro-work for six months, one hour a day for seven days a week. Even without any long-term 
employment contract, both counted on the income they had got used to receiving from platform work, and its sudden loss was hard to manage. Because the multi-layer structure and its dynamics are occluded from view, A. and F. ignore whether they were punished for making a mistake, or the platform experienced some (unrelated) order cancellations. Lazega (2020) shows that in a multi-level structure, different levels have different temporalities, and require actors to adjust. Here, platforms and clients move faster, and this a-synchrony comes to workers' disadvantage.

\section{Conclusions}

I have shown that the platform-as-market model embodied in Amazon Mechanical Turk disembeds workers, exposing them to uncertainties and lack of protections. The multi-layer model of, among others, Pactera and Appen deeply embeds workers, with better pay but also reduced flexibility, stricter discipline, and less transparency. A similar argument holds for clients. Market-like platforms offer them standardized user-friendly interfaces and off-the-shelf technical tools, with arm's length contracts in the sense of Uzzi (1997), therefore disembedded. Multi-layer platforms enable customization of technical tools and more controlled management of the workforce, but require engagement in tighter, longer-term contracts akin to Uzzi's embedded ties. These differences hold across types of online labour. Most freelancing and some micro-work platforms adopt the marketplace model (regardless of other differences between them), while only some micro-work platforms embrace the multi-layer model.

These economic network structures may or may not co-exist with social networks of workers (I-I in the language of this article). Observed in some platform-as-market cases, such networks are less likely to form with multi-layer platforms whose siloed design limits workers' opportunities to interact - though this is only a general tendency with multiple exceptions. The broader issue behind these diverse outcomes is that global competition on online labour platforms limits workers' opportunities to organize collectively, so that they 'mostly interact as competitors rather than collaborators' (Graham and Anwar, 2019). Under these conditions, metaphorically, the number of layers matters more than the number of friends - that is, the economic structure of firms' ties affects workers' conditions, productivity and outcomes more than their social networks of peers.

The discovery of deep embeddedness in the case of multi-layer platforms completes and refines the conclusions derived by Wood et al. (2019) based on Peck (2013)'s distinction between hard and soft Polanyi. In the case of marketplace-like platforms, I make the same claim of disembeddedness, but they impute this result to commodification (in the hard-Polanyi sense), while I point to the thinness of affiliation ties between individuals and firms $(I-F)$. Somewhat speculatively, my argument might be seen as an operationalization of theirs - insofar as insubstantial ties to firms mean that workers are more subject to the caprices of the market. More innovatively, I then stretch this analysis further and demonstrate the impact of the economic ties $I-F$ and $F-F$ that define workers' positions in the production process, in the previously overlooked case of multi-layer platforms. They would not be described as disembedded or commodified strictly speaking, as workers retain some of the protections that usually come with employment, but I highlight substantial imbalances of power, whereby firms influence individuals but not the other way round. In this respect, the multi-level approach is entirely consistent with a broad view of embeddedness and can smoothly integrate the hard and soft dimensions into one common scheme.

In this sense, the findings illustrated in this article contribute to research on embeddedness within economic sociology. Critics asserted that focus on just the social network of friends and kin is too narrow to really reconcile the social and economic dimensions. I submit that the multi-level network analysis approach of Brailly et al. (2016) offers a solution by combining the social networks of individuals $I-I$, the economic networks of firms $F-F$, and the (also economic) affiliation network between individuals and firms $I-F$. While grounded in a network approach, the multi-level construct also accounts for the effects of more macro factors - like those that Hess (2004) associated to 
'societal' and 'territorial' embeddedness. The institutional context affects individual workers through the corporate entities they are affiliated to. For example, the tax codes applicable to the firms $F-$ which depend on their geographical locations and the prevalent regulatory approaches - shape the $F-F$ and $I-F$ ties that can be formed, and consequently workers' conditions and well-being.

Application of these schemes to platforms suggests that economic networks may be even more important than social networks as they reveal power asymmetries that affect action. Beyond the specific context of digital platforms, this implies that the social network of peers and friends does not suffice to establish whether labour is or is not embedded, without also commenting on the economic network of firms to which workers are tied in various ways. Far from weakening the grandiose view that pervades Polanyi's work, then, the network perspective inaugurated by Granovetter (1985) does have potential to advance this programme of research.

More research will be needed to explore the functioning of multi-layer platforms in greater detail, especially the differences between a country like France and the Global South, where platform labour mingles with traditional business-process-outsourcing services. The applicability of the concept of deep embeddedness to other cases - within or outside the digital economy - will have to be probed. Nevertheless, I believe the insight provided here contributes to the (growing, but still scant) literature on platform labour, has value as an example of fruitful research at the crossroads of different literatures, and offers a fresh perspective on embeddedness. 


\section{Acknowledgements}

The data I use are from a larger study called Digital Platform Labour (DiPLab), and I thank the whole project team for insightful discussions around this common work - a key first step toward developing the ideas presented here. Preliminary versions of this paper were presented at the XXXIX conference of the International Network for Social Network Analysis (INSNA) in Montréal, June 2019, at my Habilitation to Direct Research at Sciences Po, Paris, in December 2019, and at the sociology seminar of ENSAE, Palaiseau, in September 2020. I thank discussants and attendees for their helpful and constructive feedback, and I am especially grateful to three anonymous Sociology reviewers for their thought-provoking suggestions. Any remaining errors or omissions are mine.

\section{Funding information}

The research project DiPLab has received funding from Maison des Sciences de l'Homme Paris-Saclay; Force Ouvrière, a workers' union, with Institut de recherches économiques et sociales (IRES); and France Stratégie, a service of the French Prime Minister's office. The platform Foule Factory offered logistical support, and Inria provided complementary funding. 


\section{References}

Appen (2019) What is human-in-the-loop machine learning? Blog post, 15 January. Available at: https://appen.com/blog/human-in-the-loop/

Bair J (2008) Analyzing global economic organization: embedded networks and global chains compared. Economy and Society 37(3): 339-364.

Bandelj N (2020) Relational work in the economy. Annual Review of Sociology 46: 251-72.

Barrientos SW (2013) 'Labour chains': Analysing the role of labour contractors in global production networks. The Journal of Development Studies, 49(8): 1058-1071.

Beckert J (2003) Economic sociology and embeddedness: How shall we conceptualize economic action? Journal of Economic Issues 37(3): 769-787.

Beckert J (2009) The great transformation of embeddedness: Karl Polanyi and the new economic sociology. In: Hann C, Hart K (eds), Market and Society: The Great Transformation Today. Cambridge: Cambridge University Press, 38-55.

Brailly J, Favre G, Chatellet J, Lazega E (2016) Embeddedness as a multilevel problem: A case study in economic sociology. Social Networks 44: 319-333.

Breiger RL (1974) The duality of persons and groups. Social Forces 53(2): 181-190.

Calnitsky D (2014) Economic sociology as disequilibrium economics: A contribution to the critique of the new economic sociology. The Sociological Review 62(3): 565-592.

Carruthers B, Uzzi B (2000) Economic sociology in the new millennium. Contemporary Sociology 29(3): 486-494.

Casilli A (2019) En attendant les robots: Enquête sur le travail du clic. Paris: Seuil.

Casilli A, Tubaro P, Le Ludec C, Coville M, Besenval M, Mouhtare T, Wahal E (2019) Le micro-travail en France. Derrière l'automatisation, de nouvelles précarités au travail ? Final report of project Digital Platform Labor (DiPLab).

Coase RH (1937) The nature of the firm. Economica 4(16): 386-405.

de Reuver M, Sørensen C., Basole RC (2018) The digital platform: a research agenda. Journal of Information Technology 33(2): 124-135.

De Stefano V (2016) The rise of the 'just-in-time workforce': On-demand work, crowdwork, and labor protection in the 'gig economy'. Comparative Labor Law \& Policy Journal 37: 471-504.

Favereau O, Lazega E (2002) Conventions and Structures in Economic Organization: Markets, Networks, and Hierarchies. Cheltenham: Edward Elgar.

Glückler J (2001) Zur Bedeutung von Embeddedness in der Wirtschaftsgeographie. Geographische Zeitschrift 89(4): 211-226.

Graham M, Anwar M (2019) The global gig economy: Towards a planetary labour market? First Monday 24(4).

Graham M, Hjorth I, Lehdonvirta V (2017) Digital labour and development: impacts of global digital labour platforms and the gig economy on worker livelihoods. Transfer: European Review of Labour and Research 23(2): 135-162.

Granovetter M (1985) Economic action and social structure: the problem of embeddedness. American Journal of Sociology 91(3): 481-510. 
Gray M, Suri S (2019) Ghost Work: How to Stop Silicon Valley from Building a New Global Underclass. Boston: Houghton Mifflin Harcourt.

Gray M, Suri S, Ali S, Kulkarni D (2016) The crowd is a collaborative network. Proceedings of the 19th ACM Conference on Computer-Supported Cooperative Work \& Social Computing, 134-147.

Hara K, Adams A, Milland K, Savage S, Callison-Burch C, Bigham J (2018) A data-driven analysis of workers' earnings on Amazon Mechanical Turk. Proceedings of the $2018 \mathrm{CHI}$ Conference on Human Factors in Computing Systems (CHI '18) 449: 1-14.

Henderson J, Dicken P, Hess M, Coe N, Wai-Chung Yeung H (2002) Global production networks and the analysis of economic development. Review of International Political Economy, 9(3): 436-464.

Hess M (2004) 'Spatial' relationships? Towards a reconceptualization of embeddedness. Progress in Human Geography, 28(2): 165-186.

Howcroft D, Bergvall-Kåreborn B (2019) A typology of crowdwork platforms. Work, Employment and Society 33(1): 21-38.

Ingram P, Roberts PW (2000) Friendships among competitors in the Sydney hotel industry. American Journal of Sociology 106(2): 387-423.

Krippner GR (2002) The elusive market: Embeddedness and the paradigm of economic sociology. Theory and Society 30(6): 775-810.

Krippner GR, Granovetter M, Block F, Biggart N, Beamish T, Hsing Y, et al. (2004) Polanyi Symposium: a conversation on embeddedness. Socio-Economic Review 2(1): 109-135.

Lazega E (2020) Bureaucracy, Collegiality and Social Change. Redefining Organizations with Multilevel Relational Infrastructures. Cheltenham, Edward Elgar.

Murali A (2019) How India's data labellers are powering the global Al race. Factor Daily, 21 March.

Peck J (2013) Disembedding Polanyi: Exploring Polanyian economic geographies. Environment and Planning A: Economy and Space 45(7): 1536-1544.

Polanyi K (2001 (1944)). The Great Transformation: The Political and Economic Origins of Our Time. Boston: Beacon Press.

Polanyi K (1957) The economy as instituted process. In: Polanyi K, Arensberg C, Pearson H (eds), Trade and Market in the Early Empires: Economies in History and Theory. New York: Free Press.

Pun N., Tse T., Shin V., Fan L. (2020) Conceptualising socio-economic formations of labour and workers' power in global production networks. Sociology, 54(4): 745-762.

Roberts S (2019) Behind the Screen: Content Moderation in the Shadows of Social Media. New Haven: Yale University Press.

Rysman M (2009) The economics of two-sided markets. Journal of Economic Perspectives 23(3): 12543.

Shevchuk A, Strebkov D (2018) Safeguards against opportunism in freelance contracting on the Internet. British Journal of Industrial Relations 56(2): 342-369.

Schmidt F (2017) Digital labour markets in the platform economy: Mapping the political challenges of crowd work and gig work. Report, Friedrich-Ebert-Stiftung.

Schmidt F (2019a) Crowdproduktion von Trainingsdaten: Zur Rolle von Online-Arbeit beim Trainieren autonomer Fahrzeuge. Report, Hans-Böckler-Stiftung.

Schmidt F (2019b) The design of crowdsourcing. Talk at INDL conference, Paris, 14 June. 
Snijders TAB, Bosker R (2012) Multilevel Analysis: An introduction to basic and advanced multilevel modelling, $2^{\text {nd }}$ edition. London: Sage.

Srnicek N (2016) Platform Capitalism. Cambridge: Polity Press.

Sundararajan A (2016) The Sharing Economy: The End of Employment and the Rise of Crowd-based Capitalism. Cambridge, MA: MIT Press.

Tubaro P, Casilli A (2019) Micro-work, artificial intelligence and the automotive industry. Journal of Industrial and Business Economics 46(3): 333-345.

Tubaro P, Casilli A, Coville M (2020) The trainer, the verifier, the imitator: Three ways in which human platform workers support Al. Big Data \& Society 7(1), DOI: 10.1177/2053951720919776.

Uzzi B (1996) The sources and consequences of embeddedness for the economic performance of organizations: The network effect. American Sociological Review 61(4): 674-698.

Uzzi B (1997) Social structure and competition in interfirm networks: The paradox of embeddedness. Administrative Science Quarterly 42(1): 35-67.

Vaughan J (2018) Making better use of the crowd: How crowdsourcing can advance machine learning research. Journal of Machine Learning Research 18(193): 1-46.

Wasserman S, Faust K (1994) Social Network Analysis: Methods and Applications. Cambridge: Cambridge University Press.

Williamson $O$ (1981) The economics of organization: The transaction cost approach. American Journal of Sociology 87(3): 548-577.

Wood A, Graham M, Lehdonvirta V, Hjorth I (2019) Networked but commodified: The (dis)embeddedness of digital labour in the gig economy. Sociology 53(5): 931-950.

Yin M, Gray M, Suri S, Vaughan J (2016) The communication network within the crowd. Proceedings of the 25th International Conference on World Wide Web, 1293-1303. 


\section{Biography}

Paola Tubaro is Research Professor in sociology at the National Centre for Scientific Research (Centre National de la Recherche Scientifique, CNRS) in Paris. She was previously a Reader in economic sociology at the University of Greenwich, London. A specialist of social and organizational networks, she is currently researching the place of human labour in the global production networks of artificial intelligence, and the social conditions of platform work in French- and Spanish-speaking countries. Her interests also include data methodologies and research ethics. She co-convenes the Social Network Analysis Group of British Sociological Association (BSA-SNAG). 


\section{Figures}

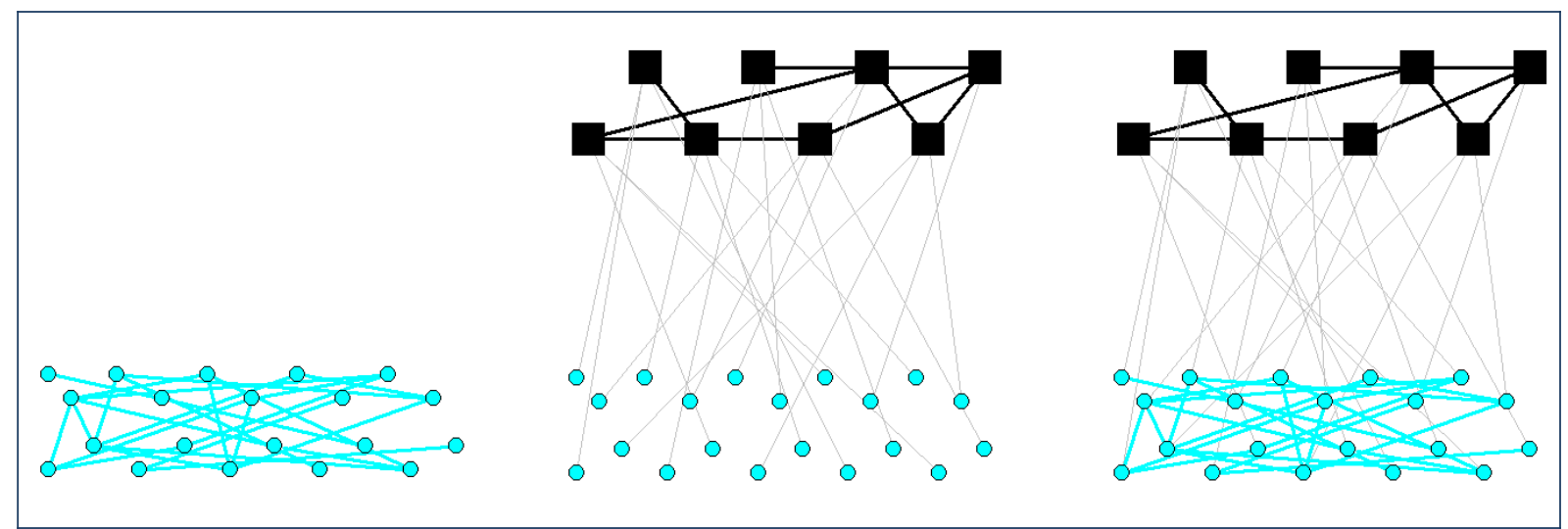

Figure 1: Dimensions of embeddedness. Nodes are actors (cyan circles = individuals, black squares $=$ firms) and lines are ties between actors (black = inter-firm ties $F-F$, cyan = inter-individual ties $I-I$, gray = individual-firm ties $I-F)$. Left: social $(I-I)$ network. Center: economic $(I-F$ and $F-F)$ networks. Right: multilevel structure of social and economic networks.

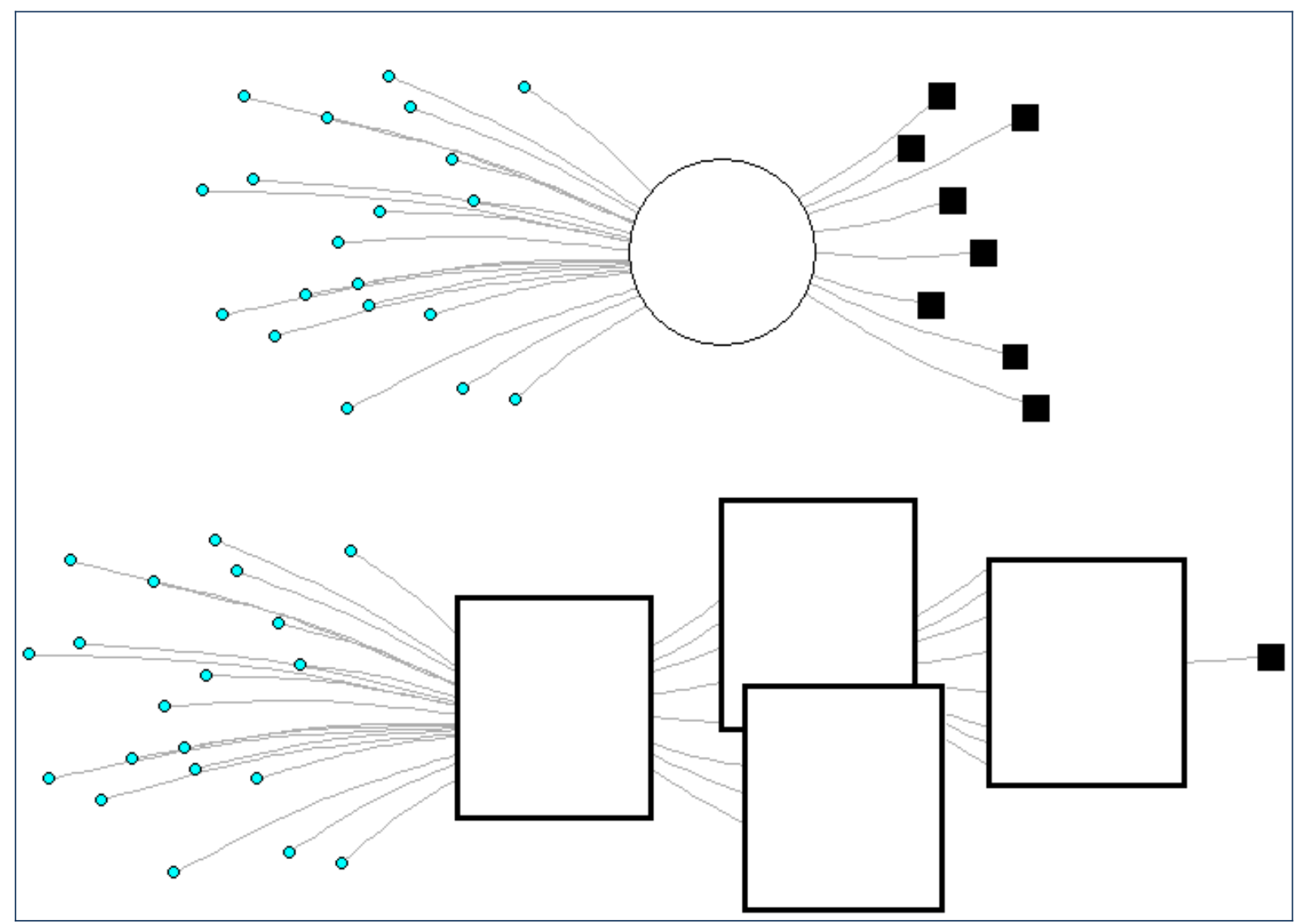

Figure 2: Two models of platform inter-mediation for micro-work. Top panel: intermediaries in market-like twosided structures of interaction. Bottom panel: firm-like multi-layer structures. Cyan circles = workers, black squares $=$ final clients, white large circle $=$ marketplace platform, white rectangles $=$ firm-like platforms, their contractors and subsidiaries. 